\title{
Editorial Dossiê
}

\section{"Artes da projeção em múltiplos canais: operacionalidades visuais e sonoras"}

Artes de proyección multicanal: operaciones visuales y sonoras Multi-channel Projection Arts: Sound \& Visual Operativities

As projeções não cessam de se propagarem, seja porque expandiram-se para além dos cubos brancos das galerias ou dos escurinhos dos cinemas; seja porque os meios tecnológicos emergentes têm facilitado as produções de imagem, de som e ambas de artefatos audiovisuais. Contudo, principalmente, porque talvez já chegamos às fábulas futurísticas de écrans diversos a emoldurarem nossas poéticas - dispositivos habituais, como aparelhos celulares ou relógios digitais, são também emissores de amplificados sinais visuais, além de sonoros, e experiências de anteparos através de água, fumaça e vapor, vidraças, tecido, vestíveis, utensílios, etc.

Sem necessidades de superfícies específicas para a projeção, pensamentos, emoções, hábitos e comportamentos são compartilhados coletivamente em nossos cotidianos, desde espaços públicos urbanos aos privados intimistas. Quanto às questões dos observadores diante das projeções, as teorias clássicas do cinema já problematizavam o espectador parado em passividade corporal no dispositivo referente, enquanto os estudos de mídiaarte pareciam apontar para uma crítica frente ao fascínio tecnológico das projeções digitais, nos deixando atentos para além dos aspectos de imersividade e/ou interatividade presentes (ou não) nas propostas artísticas.

A motivação ao presente dossiê decorre tanto de algumas práticas laboratoriais, desenvolvidas em nossos projetos universitários ao longo dos últimos anos, quanto de diálogos com pares desde diversificadas experiências. Dessa maneira, buscamos um debate às reflexões sobre os modus operandi, seus processos de criação, suas gestualidades de montagem e composição nas distintas formas (Montaner, 2002; Elsaesser, 2018) a esses projetares: qual a diferença da imersividade do dispositivo cinematográfico e dos demais em projeção? Quais estéticas "interativas" experienciamos em videoprojeções instaladas? Ou, de que maneira diferentes projeções - e seus atos de projetar, "to design" - causam distintas afecções no ser humano?

Sem oposição entre imagens mentais (sejam sonoras ou visuais) e fatos reais, de acordo com Gilbert Simondon 
(1924-1989), as imagens e as escutas projetadas, ora reguladoras, ora transgressoras, nos remetem aos aspectos de interioridade e exterioridade contidos nas mesmas, unindo imaginação (simbólica, mental, onírica, emotiva) e invenção (objetos, linguagens, figuras, sons). Há uma causalidade circular entre a interioridade e a exterioridade, que se concretiza nas práticas artísticas, nos objetos tecno-estéticos, nos monumentos e nos gestos político-sociais. Projeções, como quase-organismos que se formam no sujeito, apresentam certa autonomia: não só sujeitos produzem imagens, contudo, imagens visuais e auditivas produzem sujeitos coletivos.

Do século XVII - com o teatro de sombras -, passando pelos espetáculos de fantasmagoria (1763-1837), as lógicas da Lanterna Mágica (1870), a invenção do cinematógrafo (1895) e as vanguardas do início do século $X X$, chega-se à contemporaneidade entre historiografias e debates sobre a arte da animação (Lucena, 2002), o ilusionismo e a imersividade (Grau, 2007), a videoarte, a videoinstalação (Rush, 2006), o cinema expandido (Youngblood, 1971; Rieser, 2002) e as suas constantes atualizações entre paisagens sonoras e/ou visuais referenciadas com diferentes termos: projeção fulldome e as distintas $360^{\circ}$ (realidade virtual e além), live cinema (ou visual jockey), videomapping, multimedia installation, projeção móvel, video sculpture, grafite luminoso, projeção não-linear, projeção holográfica, composições para videowall, etc. Terminologias nas quais explicitam diversas práticas de projeção, e suas tecnologias relativas, que exploram múltiplas estéticas projetuais à imersão, navegação e/ou interação - techné, aesthesis, práxis.

Entre o excesso de exposição das imagens técnicas e a montagem como base de toda prática artística, as tecnologias emergentes intensificam, portanto, os aspectos de composição, reprodução e exibição, ao aportarem consigo necessidades referentes às novas linguagens, assim como seus modos de produção, percepção e encenação, previamente sinalizadas há um século por Siegfried Kracauer (1889-1966), Walter Benjamin (1892-1940), Dziga Vertov (1896-1954) e Sergei Eisenstein (18981948), entre outros.

No condizente às sonoridades, os artistas audiovisuais reverenciam musicalmente as articulações desde compositores concretos aos performáticos eletro-acústicos, trabalhando entre silêncios, ruídos e/ou spoken words - como John Cage (19121992), Karlheinz Stockhausen (1928-2007), Robert Moog (19342005) e Laurie Anderson (1947-). Tais artistas, como os criadores contemporâneos em música eletrônica, Amon Tobin e Xerxes de Oliveira, viram ampliadas suas possibilidades às luzes da "afinação do mundo" entre paisagens sonoras, escutas e acústicas dos 
objetos e ambientes nessa arte do tempo (Schafer, 2001; Wisnik, 2017) em comunhão às práticas de remix - entre samples, loop e scratching, etc. - tanto no exterior (Dworkin, 2003; Lessig, 2008; Navas, 2012) quanto no Brasil das aparelhagens (Lemos, 2008).

Ao explorar topologias diversas - tais como empenas cegas, CAVEs, domes, planetários, galerias, distintos objetos, corpos, vegetações, etc., diferentes artistas investigaram múltiplos aspectos do ato de projetar (Artigas, 2015). Por exemplo, enquanto Hélio Oiticica, Bill Viola, Pipilotti Rist, Eder Santos, Willian Kentridge, Eija-Liisa Ahtila e Douglas Gordon trabalham a imersividade em suas instalações com múltiplas telas em blackboxes de galerias, artistas como Grahame Weinbren, Myron Krueger, Jeffrey Shaw, Peter Weibel, Golan Levin, Ryoji Ikeda, Lucas Bambozzi, Sandra Kogut e a dupla feminina mm não é confete, historicamente, instigaram seus espectadores a se tornarem participadores, interatores ou, ainda, interactants (entre Neville d'Almeida, Julio Plaza, Lev Manovich e Bill Seaman); ou seja, a agirem nos variados níveis de interatividade junto às obras - uma chamada do sujeito para a ação. Se artistas como Anthony McCall, James Turrell, Marc Lee e Joan Jonas realizam outros modos de interferências espaciais em galerias ou na web, Daniela Kutschat, Studio Azzurro, TeamLab e Tony Oursler trabalham projeções com lógicas de CAVEs a video sculptures, já artistas como Rafael Lozano-Hemmer e Roberta Carvalho, entre outros, exploram desde arquiteturas relacionais a intervenções nas paisagens urbanas ou naturais.

Propusemos, desta maneira, um dossiê com contribuições que colocassem luzes sobre os métodos, estruturas e práticas a partir dessas e outras experimentações, relacionadas às reflexões quanto observadores e percepção (Crary, 2013) ou da natureza do espectador em projeção (Mondloch, 2010; Simanowski, 2011). Nessas inúmeras maquinarias e práticas artísticas (Machado, 2001), dentre os múltiplos meios que se associam através de experiências sócio-estéticas e as operações que se propagam no ato da projeção, questiona-se:

\section{Quais operações permeiam o ato de projetar realidades? \\ Para cada modalidade, uma projeção? Como articulam-se áudios e imagens entre observadores $\mathrm{e}(\mathrm{m})$ diferentes meios?}

Ao trazermos o ato de projetar (Flusser, 2007), nos desviamos de modelos identitários e deterministas tecnológicos, voltandonos ao aspecto relacional que constitui toda prática artística, aos 
criatividade à projeção, como experiências imagéticas visuais e sonoras. Ato de projetar mundos extra-particulares que criamos de acordo com nossas experiências tecno-estéticas - imagem / interface / dispositivo / projeção - estão sempre se alterando entre representação e controle pela ação do sujeito (atividades corpoespaciais no ato de projeção, da contemplação e participação à interatividade - jogo de gestos e olhares do público).

Portanto, para além do excesso tecnológico fetichizado - malabarismos digitais através da imagem tridimensional computadorizada - buscávamos também contribuições quanto à imersividade, participação ou interatividade propostas pelas experiências topológicas em projeções na arquitetura: tanto específicas como as abóbadas, projetores e sistemas sonoros para fulldomes quanto as caracterizadamente tratadas como intervenções urbanas ou além.

O presente dossiê na Revista Vazantes, Artes da projeção em múltiplos canais: operacionalidades visuais e sonoras, recebeu contribuições de pesquisadores e artistas desde suas problematizações, experimentações e reflexões pertinentes a tais práticas no campo da Arte, ontem e hoje, a fim de expandirem os diálogos do conhecimento entre processos visuais e sonoros em projeção, conforme listamos na original chamada em 2020:

- Projeções em planetários, arquiteturas domes ou localidades específicas - o lugar do observador nos simulacros projetivos (e.g. fulldome, 360, VR - realidade virtual, CAVE, etc.)

- Apropriação política do espaço urbano - projeções na cidade como um ato cidadão (e.g. videomapping, grafite luminoso, projeções móveis, vj'ing - visual jockey, etc.)

- Das historiografias de projeção ao estado-da-arte - questões contemporâneas do digital, ou não, no Brasil e no mundo (e.g. imagens holográficas, vídeo-instalações, filme-ensaio projetivo, lógicas do banco de dados, etc.)

- Instalações das projeções em fluxo em espaços expositivos (e.g. cinema de exposição e as lógicas do loop, visualização de dados, inteligência artificial, etc.)

- Projetando o som além da imagem (e.g. paisagem sonora, instalação acústica, estereofonia, desenho de som, etc.)

- Práticas coletivas e colaborativas no ato de projetar (e.g. projetos e processos coletivos para projeção em distintos dispositivos audiovisuais.)

- Arquitetura e topologia do espaço em desconstruções projetivas (e.g. video sculpture, videowall, video projection, etc.)

- O espaço relacional em projeções audiovisuais (e.g. 
performances telemáticas, happenings, etc.)

- A estética interativa nas pós-cinematografias (e.g. exibições com remote control nas mãos do público, videoinstalações ou projeções com diferentes sensores para manipulação dos dados em tempo real, etc.)

- Aspectos estéticos e/ou sociais do cinema expandido história, experimentações e reflexões (e.g. motion graphics, visual music, live cinema, experimental cinema, etc.)

- Diferentes temporalidades cinematográficas nos blackboxes dos cubos brancos (e.g. múltiplos écrans, videoinstalações, etc.)

- Visualidades e sonorografias em estéreo nas diferentes mídias audiovisuais (e.g. kynect typography, visual music, experimental cinema, etc.)

- Outros ambientes para projeções assimétricas e/ou experimentais - questões online entre múltiplas mídias audiovisuais (e.g. gifs, stories, youtubers, etc.)

Desta maneira, recebemos sete artigos específicos ao tema proposto neste dossiê além de tangenciais ensaios e entrevista advindos ao fluxo contínuo da Revista Vazantes. Paulo Bernardino, ao relacionar as imagens aos seus aparatos técnicos nos direciona aos artefatos audiovisuais em seu ensaio Operacionalidades visuais: a intencionalidade através da imagem e a sua dimensão artística, enquanto Felix Rebolledo Palazuelos traz a gagueira como modo de operar a identidade coletiva na obra cinematográfica em Tarkovsky's Mirror: discursive fragmentation as stuttering. As mídias interativas e locativas, as artes e o Projeto Paraty.io: narrativas de realidade mista trata-se de um relato de Hermes Renato Hildebrand sobre o potencial artístico dos meios emergentes, enquanto Wagner de Souza Antonio e Reinilda Minuzzi nos conduzem a experiências audiovisuais sensíveis às luminâncias em Luz debruçada em superfícies: processos audiovisuais na Arte enquanto projeção mapeada. Claúdia Mariza Mattos Brandão lança seu olhar ao ato de projetar em uma poética com Transbordamentos visuais e suas sonoridades. No artigo Narrativas navegáveis: o espaço como protagonista nas instalações audiovisuais, Cristiane Ventura e Lara Satler pensam o cinema expandido a partir das metodologias e práxis de seus processos poéticos, enquanto Confesionario têxtil tece potências e segredos entre bordados, patchwork, motores e luzes de LED em memória às oficinas da professora Mariela Yeregui junto a Jacqueline Alvarado, Nuria Díaz, Hannia Durán, Emily Navarro, Raquel Navarro, Laura Ramírez, Noelia Guzmán.

$\mathrm{Na}$ seção de entrevistas, Wilker Paiva dialoga com o artista suíço Marc Lee questões de Echolocation, Arte/ Tecnologia. A 
seção de proposições poéticas do dossiê é brindada com Arquivos de si, de Ana Maio - onde transitamos por memórias híbridas que perpassam narrativas, arquivos e videoprojeções -, com Rádio Pirata no meio da mata, onde Xan Marçall peregrina poeticamente - "chapando a cabeça, queimando a pele" - nas ondas sonoras da TransAmazônica, com Experimento Metamorfa \#3 - Corpa em (trans)projeção, de Leonardo Zingano e Levi Mota Muniz, onde se multiplicam sobre um híbrido corpo-projeção, enquanto Vinícius Bandeira transita entre o filme e o romance por narrativas, telas, montagens e personagens históricos através da experimentação poética No cinema como na literatura. Já O Guarda-chuva: arte, paisagem sonora e a cidade de Belém, de Raymundo Oliveira, encontramos a paisagem sonora relacionada ao espaço aumentado e à mensagem estética via instalação interativa. Na seção de tradução, os processos artísticos e culturais encontramse com métodos para visualização de dados, em particular os gestos de montagem em Dziga Vertov, conforme proposto por Lev Manovich no texto Visualizando Vertov. Inédito em português, foi traduzido pelos bolsistas do Projet'ares Audiovisuais há três anos (apoio PAIP, PID e SECULT- ARTE- UFC) e que este dossiê na Revista Vazantes traz agora à publicação acadêmica brasileira.

Contentes com mais esta parceria ao compartilhamento colaborativo entre Artes, desejamos a todes excelentes leituras!

\section{Andreia Machado Oliveira e Milena Szafir}

